felt pulsating, I found it quite impossible to obtain sufficient view to enable me to pass a ligature. This difficulty was due largely, if not entirely, to the fact that we had been unable to get the patient into a proper Trendelenburg position. The table used had not the necessary adjustment for this position, and attempts to obtain it by raising the pelvis with sandbags and pillows had not been very successful since we did not like to apply much pressure in the neighbourhood of the aneurysm. Moreover, the flexion of the hip tilted up the thigh to an awkward angle when the pelvis was lifted to any great extent. Under the circumstances I was compelled to enlarge the wound by making a short transverse incision, and even then had to withdraw a good deal of intestine from the abdomen before I could obtain a view of the spot where the arteries lay beating behind the posterior peritoneum.

Here the second diffoulty presented itself. I found that I was in considerable doubt as to which was the internal iliac artery in considerable doubt as to which was the internal iliac artery deal of trouble it was found that the anatomy of these was as follows: The right common iliac divided rather above the lumbo-sacral articulation into its two divisions. Of these, the true external iliac lay at first internal to the other, and disappeared almost at once into the pelvis. It soon reappeared, running forwards along the pelvic brim, and finally curved sharply outwards, almost at right angles, to Poupart's ligament, behind which, as already noted, it passed $I$ in. external to its usual position. The true internal iliac was at first placed external to the external, and ran down along the inner border of the psoas above the pelvic brim. Bhortly beyond the point at which the external artery appeared out of the pelvis, it crossed in front of this latter and continued its usual conrse down into the pelvis. All this was very puzzling to make out, as one was working at the bottom of a deep wound, and had to as one was working at the bottom of a deep wound, and had to depend as much on one's sense of touch as that of sight. How-
ever, having at length ascertained the course of the vessels and ever, having, at length ascertained the course of the vessels and
confirmed this by noting the effects of compression on the confirmed this by noting the effects of compression on the
pulsations of the femoral in the thigh, I snipped through the peritonenm covering the internal iliac sipery and with an aneurysm needle passed a double thresd of No. 8 silk around it. This required some little care, so as to avoid wounding the vein. The ligature was then tied as tightly as I dared (the artery was somewhat calcarèous and rigid), completely stopping pulsations below, though a curious thrill could be felt at the point of the ligature as if from a minute squirt of fluid. The fittle slit in the peritoneum was next roughly .brought together by a single stitch, the intestines returned, and the abdomen closed in the usual way. Examination of the buttock showed closed in the usual way. Examination of the butto

There was some shock following, necessitating infusions by the rectum, but after the first twenty-four hours the patient's the rectum, but after the first twenty-four hours the patient's
progress was uninterrupted. Recurrent pulsation in the progress was uninterrupted. Recurrent pulsation in the aneurysm commenced, however, two days after the operation. collateral circulation. These pulsations were never very marked, though persistent. The patient was given potassinm iodide, and the aneurysmal swelling gradually became smaller and-the most sitisfactory point-increasingly harder. The pain was also considerably lessened. The patient left the hospital about six weeks after the operation.

I saw the man at his own home about four weeks later. He was then able to walk about his cottage comfortably, and said that the pain had quite left his thigh, and was only felt to a moderate degree along his leg and foot. The aneurysm could still be felt to pulsate, but not markedly. It was smaller than before the operation, and felt quite hard.

I have called this a case of gluteal aneurysm, though I am not prepared to assert that this vessel was involved rather then the sciatic. Indeed, from the rather low position of the most prominent part of the enlargement, and from the way in which it pressed upon the great sciatic nerve, a sciatic aneurysm is rather suggested. When, however, the swelling has reached the size that this had it is impossible to distinguish between the two, nor is there the least necessity to do so; and the term "gluteal" is a convenient one to apply to anything pertaining to this region.

The diagnosis of aneurysm in this position from a palsating sarcoma may be quite impossible, but in this casse the slow growth, the uniform consistency of the lump, and the marked thrill, made us feel pretty certain we were dealing with the former condition; this was confirmed by the result of the operation, though against this must be quoted a very instructive case recorded by $\mathrm{Mr}$. Bernard Pitts, in which marked temporary improvement was brought about in a vascular pulsating sarcoma in the gluteal region by ligature of the internal iliac. ${ }^{1}$

In performing the operation the transperitoneal method was selected (as, I should imagine, it would al ways be in these days), as being by far the simpler, easier, and safer way. As Sir Frederick Treves says: "The advantages of this method are obviouf. The vessel is fally exposed, and the needle can be passed without risk to vein or ureter. The ligature can be applied accurately at the spot determined upon, and the condition of the artery and the surrounding parts can be made out." 2
One of my difficulties was to obtain a clear view of the posterior peritoneum covering the vessels, owing to the bulging intestines. On the left side this difficulty might be increased if the sigmoid flexure were fixed by a narrow mesentery, for the mesentery would then have to be in cised before exposure could be effected. The importance of the Trendelenburg position cannot, I think, be exaggerated.

The abnormal condition of the vessels which caused my other chief difficulty could not, of course, be guarded against. It must be remembered, however, that an abnormal arrangement of the iliac arteries is not very uncommon. Mr. Bernard Pitts, in operating on the case of sarcoma mentioned above, ${ }^{1}$ says that he at first failed as he thought to find the internal iliac artery. He continues, "Having failed ... I I exposed and ligatured what I believed to be the common iliac, but after drawing the ligatures tight it was found that pulsations still continued in the femoral artery. Further examination showed that the external iliac artery was lying just outside the vessel ligatured. The common iliac was very short and the internal was correspondingly long and lying in almost the whole of its course above the brim of the pelvis parallel with the external vessel."

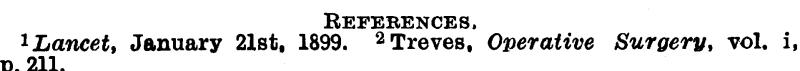
p. 211 .

\section{AMPUTATION FOR DIABETIC GANGRENE.}

BY

A. E. JOHNSON, M.B.; Ch.B.Vict., F.R.C.S.Eng., RESIDENT MEDICAL OFFICER, MIDDLESEX HOSPITAL, $w$.

Amputation for diabetic gangrene is an operation always attended with danger, and is a cause of much anxiety to the surgeon. The following case is reported as illustrating precautions which may be taken to ensure, as far as possible, a successful result.

A married woman, aged 62, was admitted to the Middlesex Hospital under the care of Mr. Sampson Handley on September 3rd, 1908. She was saffering from moist gangrene of the left lower extremity. The gangrene extended above the ankle, the skin had given way at many places, and there was considerable discharge of pus. She was extremely feeble, the pulse was 120, and the temperature $98^{\circ}$

For the previous three years the patient had not had complete control over the bowels and bladder, and had suffered from troublesome vomiting. She had had a terrible thirst for three years, had complained of polyuria, and had wasted considerably. The urine had a specific gravity of 1030, and it contained The urine had a specific gravity of 1030

Wumen, some pus, and 2 per cent. of sugar. to the ward reserved for septic cases, as he did not consider that she would stand an amputation of the limb, but later he consented to my attempting it, and kindly entrusted the case to my care. Under local anaesthesia I exposed the anterior crural nerve, and Mr. D. Ligat exposed the great scistic. Into the sheaths of these nerves was injected a solution of novocain, and the incisions were gutured. Dr. F. E. Mesdows then administered a mixture of nitrous oxide gas and oxygen for about eight minutes, and I amputated the limb at the junction of the lower and middle thirds of the thigh. The patient at once recovered from the anaesthetic, and was quite comfortable, complaining of no pain. Her pulse was certainly no worse, but, if anything, no pain. Her pulse was certainly no worse, but, if andeses of sodium bicarbonste were given per rectum as a prophylactic messure against the onset of coms.

There was nothing in the convelescence calling for special notice except that the site where a drainage tube had been inserted showed no attempt at healing for some time; in amputation-that the stump could be said to be absolutely healed.

Under medical treatment the patient's general condition improved somewhat. Examination of the urine on October 14th showed that there was less than 1 per cent. of sugar, with some pus, and on October 19th that there was only a trace of sugar,

The patient never recovered sufficient strength to use her crutches, and the circulation in the right lower extremity gave some canse for anxiety. She left hospital on November Ilth for her own home, where she was to remain in bed. She was, I \&m informed, comfortable and happy at home for about three months, when she began to lose ground again. She died of coma
on April 17th, 1909-over seven months after the ampatation was performed.

NOTE BY MR. HANDLEY.- " The condition of this patient before operation appeared desperate, and the favourable issue of the case affords the clearest possible proof of the value of the methods employed." 
The special dangers attending amputation for diabetic gangrene may be classified under three heads-dangers from the anaesthetic, dangers from shock, and dangers of sepsis.

In diabetes there is such interference with carbohydrate metabolism that sugar cannot be used; it is not united with the protein of the tissue cells or blood serum, and being a diffusible substance, this free sugar is immediately excreted in the urine. The interference with carbohydrate metabolism leads to a call for other foods, and the condition described as fatty liver may be produced. The presence of histologically visible fat in the liver cells may be due (1) to the dissociation of fat, which was already in the liver, from its loose chemical union with the protein of the bioplasm, in which form it was histologically invisible bat ascertainable chemically ; or (2) the fat may have been transferred to the liver from the subcutaneous and otber fat stores for the purpose of being prepared for the requiretnents of those organs and tisenes where it is to be used. ' Possibly both processes occur, but in neither "csse can the condition be accurately described as a "fatty degeneration." If the extra call on the fats of the body be great, their metabolism is likely to be incomplete owing to the inability of the bioplasm to make full use of them, and if the lower fatty acids be thrown into circula. tion, their presence will be shown at once by their appearance in the urine. This statement is made on the assumption that the fat is to be used as fat and that its catabolism is incomplete. If, however, as Pflüger believes, sugar, which cannot be accounied for by the carbohydrates of the foods or tissues, be formed from fat, the presence of the lower fatty acids might be explained by their being provided for the purpose of sugar synthesis.

It is generally acknowlodged that it is acidosis, due to the eirculation of fatty acids, which is, in some way, responsible for the onset of diabetic coma. Pavy! says :

Sugar, in proportion as it is present in the blood, produces toxic effects of various kinds, which may lead indirectly to death, but it does not, in a direct manner, kill. With regard to the acids belonging to the acetone series, however, the same cannot be said. Their effect in the blood is to interfere with the performance of one of the necessary functions of life.

This vital function is the elimination of carbon dioxide. The alkalis of the blood, sodium carbonate and sodium phosphate, are, to a certain extent, neutralized by the fatty acids, and so there is less available for the conveyance of carbonic acid from the tissues. This leads to a diminution of the carbon dioxide content of the blood and an accumu' $\mathrm{A}$. tion of carbon dioxide in the tissues, which, in Pavy's view, leads to the onset of coma. It may be as Pary states, or, on the other hand, the supervention of coma may be due direotly to the acidosis, as maintained by Beddard, Pembrey, and Spriggs. ${ }^{2}$

Since acidosis is in some way responsible for the onset of diabetic coma, and since post-operative coma, according to Roff, occurs in diabetes in 106 per cent. of cases, it is essential that the surgeon should avoid every possible cause of the supervention of acidosis or the increase of it if present.

Special calls leading to increased fat combustion may be very slight, such as the adoption of a too strict dietary or starvation before operation. To quote $\mathrm{Pavy}^{8}$ again :

We know how easily through the general state the acetone bodies may be increased. A severe attack of migraine, for instance, may send them up, and influenza pneumonia, etc. may do so sufficiently to suddenly bring about the supervention maj do

How wuch more may a surgical operation prove disastrous especially if performed under the influence of an anaesthetic which may itself lead to the condition of acidosis!

Bat there are some operations which must be performed on diabetics, and it is the method of their performance that must be looked to to prevent a fatal termiuation. A certain amount of disturbance of fat metabolism occurs quite commonly after the administration of anaesthetics, as is shown by the frequent appearance of acetone and di-acetic acid in the urine. Acidosis has been noticed after the administration of chloroform, ether, and ethyl chloride, but the disasters have occurred most frequently after chloroform, which has led to the use of the term "delayed chloroform poisoning." The more serious results from chloroform are probably due to the marked effect of that drug on the liver, and also to its effect on the kidnejs preventing the rapid elimination of the products of incomplete metabolism, or possibly the materials for sugar synthesis. Fatty changes in the heart, Jiver, and kidneys have been produced experimentally by the administration of chloroform, and it has been shown that a single pro. longed anaesthesia with chloroform induces fatty changes in the liver. Moreover, cases of post-anaesthetic fatty acid intoxication have been noticed especially in conditions associated with fatty changes in the liver, such as diabetes, sepsis, rickets, alcoholism, starvation, malnutri. tion, and the cyclical vomiting of children.

The anaesthetic, then, is clearly one item in an operation on a diabetic patient which requires carefal choice, and chloroform is universally avoided; but since ether also leads to acidosis, it may in the same way be a source of danger, and diabetic coma has been seen to ensue soon after its use. If a general anaesthetic must be given, nitrous oxide and oxygen will prove sufficient for most operations of necessity on diabetics; and if such anaesthesia be not long enough, resort should be had to local, regional, or spinal analgesia. The anaesthetic difficulties and dangers may thus be overcome, and the central nervous system also protected from impulses from below, and shock prevented or diminished.

Though it is now over eleven years since Bier first injected cocaine into the spinal theca, for many reasons spinal analgesia has not been generally adopted. This is a matter for congratulation, for of all the advantages which the younger surgeons of to.day inherit from their seniors.and predecessors, there is none which should be so prized and so carefally preserved as the confidence and esteem of the public. That may indeed be said to represent the crowning reward of years of labour. By a wise conservatism this confidence has been gained, and it is a truism to say that nowadays most patients submit themselves to treatment by surgical measures with perfect confidence, looking forward to the operation with hope instead of dread.

Conservatism and old fogeyism must not be confused, however, and no better distinction can be found than that drawn by Professor Osler, who has said, "Conservatism and old fogeyism are totally different things. The motto of the one is 'prove all things and hold fast that which is good'; and of the other, "Prove nothing, but hold fast that which is old.'"

Spinal analgesia has great advantages in certain conditions, but, if only from the very fact that the patient is conscious, it has also grave disadvantages, and it is questionable whether it will ever replace general anaesthesia as a routine practice. No more suitable case could be found for its use, however, than that of an amputation for diabetic gangrene. It is the universal experience of those who bave adopted it that there is no shock from operations performed under its influence, and thus the dangers from shock and those from a general anaesthetic may be overcome by the one procedure, though, of course, all the usual precantions against the onset of shock must also be taken. In the case which has just been described, nerve blocking was used, and unconsciousness was induced by the administration of nitrous oxide gas. At the date of the operation there were reports of accidents and even disasters occurring under spinal analgesia which led the writer to prefer nerve blocking. Other inducements to use nerve blocking were the reports of cases where it had been extremely successful, notably in a case of interscapulo-thoracic amputation reported by Rutherford Morison. ${ }^{4}$ Spinal analgesia, however, has now become more established, and though there seems no good reason to adopt the method as a routine practice its use in suitable cases is of the greatest value. There is a large field for its employment in cases where a general anaesthetic is contraindicated by some disease of the heart or lungs or in conditions associated with fatty changes in the liver and other organs. Also, as pointed out in a leading article in the British Medical Journal for January 15th of this year, "there is a class of patient for whom the dread of losing consciousness is itself a bar to all but life-saving operations. Then there is the advantage that, if put to it, the anaesthesia can be induced by the operator even if he be single-handed." This last advantage should make the method especially usefal in military work or in cases requiring operation at sea. The possibility of using a 
combination of spinal analgesia with a light general ansesthesia must not be lost sight of. Such a plan, like the adoption of nerve blocking and nitrous oxide anaesthesia, would seem to combine the advantages of both methods.

The dangers from sepsis in cases of diabetes lie in the special liability of such patients to septic conditions, due to the poor nourishment of the tissues owing to endarteritis, the interference with the proper nerve supply owing to neuritis, and the presence of free sugar in the blood and tissues forming a good breeding ground for micro-organisms. These dangers require special precautions apart from the ordinary measures taken in every surgical operation. For example, the emplopment of a tourniquet is best avoided, and every effort should be made to prevent bruising of the tissues from rough handling. The question of drainage is a serious one. In the case reported the drainage opening would not heal for some time and was exceedingly sluggish and indolent in appearance. Sinclair White ${ }^{5}$ has recom. mended that "drainage should be unnecessary if haemostasis has been properly attended to." While considering such a practice to be somewhat risky, since a collection of fluid in the flaps would be a source of more danger than the insertion of a drainage tube, I cannot but think that the drainage opening should be small, and that a suture should be inserted ready for tying when the tabe is removed.

REFERENCES.

1 Pavy, Lancet, December 12th, 1908, p. 1735. 2 Beddard, Pembrey, and Spriggs, Lancet, June 19th, is09. 8 Pavy, Lancet, December 12th, 1908, p. 1737. 4 Rutherford Morison. BRITIsH MEDICAI JouRNA November 25th, 1905. 5 Sinclair White, Lancet, Novenber 30th, 1907.

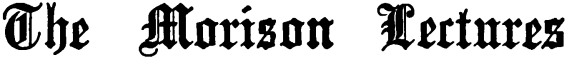

oN

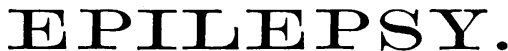

Dalivered before the Royal College of Physicians OF EDINBURGH.

BY

WILLIAM ALDREN TURNER, M.D. PHYSICIAN TO KING'S COLLEGE HOSPITAL AND PHYSICIAN TO AND FPIIEPTIC, QUEEN SQUARE, LONDON.

LeCtURE II.-Thr Problem of Epilepsy (continued). TOXAEMIC EPILFPSY

IT has for a long time been contended that an excitant of epileptic seizures might bo fonnd in toxic or autotoxic causes arising in connexion with the body metabolism or gastro-intestinal disorders. The discrepancies, however, in the results of observations by different workers upon urinary and blood toxicity in epilepsy have not afforded satisfactory evidence upon which to found such a theory. It is now generally accepted that the altered condition of the urine and blood which has been found in association with epileptic attacks by many observers is the temporary effect and not the cause of the seizures. Some explanation of these variations may be found in differences in the nature of the cases upon which the researches were carried out. Changes have not been found in the minor. or "petit mal," type of the disease. Those cases which have shown the most pronounced reactions both of blood and urine have been instances of serial epilepsy, the status epilepticus, and fits accompanied by acute mental sym. ptoms-types of the disease in which, from the general constitutional distorbances, there is more reason to suspect an infective or toxic cansation.

Binswanger ${ }^{1}$ has called attention to a small group of epilepsits which may have a toxaemic basis. This group is characterized by-

(a) Well-marked premonitory signs, of which the most common are of a psychical type; irritability, fitfulness, quarrelsomeness, lethargy, somnolence and delusions.

(b) Fits of frequent occurrence developing either into serial epilepsy, or the status epilepticas, accompanied by constitutional disturbances, such as furring of the tongue, constipation, acceleration of the palse and elevation of temperature. (c) More or less prolonged intervals free from attacks between the seizures.

I pass over with a mere reference the observations of Voison and Peron, ${ }^{2}$ who found a hypotoxic condition of the urine before and a bypertoxic condition after the fits ; of Haig, ${ }^{8}$ who laid stress upon the relation of epileptic fits to the normal diurnal variations in the excretion of uric acid; and of Krainsky, ${ }^{4}$ who attributed the convalsions of epilepsy to the formation of carbamic acid, one of the derivatives of urea.

The presence of cholin in the blood and cerebro-spinal fluid of epileptics was originally described by Donath. This substance, which was found by Mott and Halli. burton ${ }^{6}$ in the cerebro-spinal flaid in organic nervous disease, was attributed by them to disintegration of the myeline sheaths of the nerve fibres. Some observers bold that this is the cause of convulsions, owing to its toxic action, as it has also been found in cases of general paralysis with epileptiform seizures. On the other hand, it has been looked upon as the result of the fits: It bas been shown experimentally (Dide, Donath) that moderate doses of cholin injected in to tbe circulation do not produce convalsions, but that in large doses both convolsions ard paralysis may result. Buzzard and Allen' showed that the large doses of cholin necessary to produce convalsions in animals were much in excess of what could be pro. duced under ordinary conditions in man. In a recent paper Donath ${ }^{8}$ records the results of his experiments into the convulsion-producing properties of the substances found in the blood and urine of epileptics. He showed that when injected into guinea-pigs and doge, uric acid, neutral urate of sodium, carbonate of ammonium, kreatip; and lactic acid were entirely innocuous. The only convulsion-producing substances were ammonia and the organic ammonium bases-trimethylamin, cholin; kreatinin, and gaanidin; the last body is not found in human urine, but is one of the uric acid products.

A generally recognized feature of infection is increased coagulability of the blood. Dr. John Turner ${ }^{9}$ has shown (1) that the average rate of coagulation is quicker in severe cases of epilepsy; (2) that the rate is quickened during the period that the patient is having fits (serial epilepsy); (3) that there is a further quickening of the coagulation rate up to twenty-four hours before a seizure; and (4) that, from twenty-four to forty-ejgbt hours after a fit, there is a rebound and retardation in the rate of blood corgulation.

Intravascular clotting occurs clinically in cases of infection, most probably as a result of the liberation of nucleo-proteid. Dr. John Turner ${ }^{10}$ has suggested that just before an attack the leucocytes and blood plates shed their nucleo-proteid. In consequence a byaline material is found in the smaller arterioles and capillaries, obstructirg the free course of the circulation. These appearances are most conspicuous in the brains of persons dying in status epilepticus, as well as in general paralytics in whom epileptiform attacks have occurred. It is, therefore, rot improbable that some types of epileptic convulsions, notably serial epilepsy and the status epilepticus, may be associated with nucleo-proteid thrombosis arising from toxaemic influences within the body. A further sign of toxaemia, described by Lewis Bruce as occurring in some forms of acute insanity of toxic origin, is a hyperlevco cytosis associated with a high percentage of polymorphonuclear cells. It would appear from the observations of Pugh and Bruce that a hyperleucosytosis was found in cases of serial epilepsy, and those complicated with acute mental symptoms.

The general conclusion, tberefore, which might be drawn from these observations, is that the type of epilepsy due to toxic causes may be found in those acute forms of the disease known as serial epilepsy and the status epilepticus. These may, therefore, be regarded as accidental occurrences in the course of the disease.

The Immediate Causes of Epileptic Seizures.

It has been observed that the onset of an epileptic fit may be accompanied by a temporary cessation of the heart's action and the pulse beat. This transient stoppage is attri. bated to cardiac inhibition; the loss of consciousness and the fit to the resulting sudden cerebral anaemia. The most recent advocate of the cardiac inhibition theory of the cansation of epileptic seizures is Dr. A. E. Russell, ${ }^{11}$ who 